\title{
Digital assets for project-based studies and data-driven project management
}

\author{
Gloria J. Miller \\ Managing Consultant \\ maxmetrics \\ Heidelberg, Germany \\ https://orcid.org/0000-0003-2603-0980
}

\begin{abstract}
Projects offer learning opportunities and digital data that can be analyzed through a multitude of theoretical lenses. They are key vehicles for economic and social action, and they are also a primary source of innovation, research, and organizational change. This research involves a survey of digital assets available through a project; specifically, it identifies sources of data that can be used for practicing data-driven, context-specific project management, or for project-based academic research. It identified four categories of data sources communications, reports/records, model representations, and computer systems -- and 51 digital assets. The list of digital assets can be inputs in the creation of project artifacts and sources for monitoring and controlling project activities and for sensemaking in retrospectives or lessons learned. Moreover, this categorization is useful for decision support and artificial intelligence systems model development that requires real-world data.
\end{abstract}

\section{INTRODUCTION}

$\mathrm{P}$ ROJECTS offer rich environments for conducting research and learning $[1,2]$ and for practicing datadriven, context-specific project management [3]. They are a key vehicle for economic and social action, and a primary source of innovation, research, and organizational change $[4,5,6]$. They can involve budgets larger than the gross domestic product of a small nation and resources greater than the organizations participating in them [1].

The scale, complexity, uncertainty, and geographic distributions of projects are some of the factors that make projects interesting for analysis through a multitude of theoretical lenses [6]. Projects can be explained and studied using philosophical underpinnings such as the Newtonian understanding of time, space and activity, through the project archetypes such as project-based organizations, project-supported organizations, or project networks, or through the investigation of the changes in project processes or actors $[4,5,6]$.

The variety and richness that make projects interesting to study, however, can make them a challenge to efficiently manage. First, there are more than 108 well-known project-specific tools and techniques available to manage project. Besner and Hobbs [7] determined engineering and construction projects are typically large and well-defined for external customers whereas software development projects are relatively small and simple. However, since cost overruns occur in all types of projects, a project that is well-defined is not necessarily efficiently managed [8]. Second, the broad selection of tools demonstrates the multitude of factors managers must consider to plan, monitor, and control projects. Third, although collecting lessonslearned and implementing improvement processes are central concepts in project management standards $[9,10,11]$, the learnings rarely happen or do not deliver the intended results [12]. Finally, the administration of projects is moving away from documents to managing task infrastructure through digital information [13].

Researchers have begun to argue that real-time project data should be used in stakeholder engagement [14], performance management $[3,15,16]$, monitoring and controlling [17], and policy setting. These approaches support project management, moving from individual humanbased decisions to expert decisions to utilizing artificial intelligence. For example, Snider, Gopsill, Jones, Emanuel and Hicks [3] argue that project performance should be evaluated based on an analysis of the data artifacts produced from everyday project activities rather than relying on managerial understanding. Nemati, Todd and Brown [18] explain that project estimation is suitable for an artificial neural network given the numerous potential project configurations. Willems and Vanhoucke [17] found artificial intelligence was used at the front-end of projects but suggested its use has been less investigated during projects. The transitions to these data-driven methods are supported by the growing importance of digital workflows and analytics in project delivery [13].

Thus, even though projects are rich grounds for research and the push towards data-driven project management, the topic of digital data - structured and non-structured - in projects is not sufficiently covered in project management literature. This research involves a literature review to compile a list of digital assets available through a project context. A digital asset classification would be valuable to project researchers and to project managers moving towards data-driven project management. Thus, the study 
provides a conceptual model for incorporating expert systems and artificial intelligence into the project management process. While there are individual studies that provide some insights into the sources of project management data and the project management standards provide document lists, there is no comprehensive list of project-specific digital assets available in the literature. Furthermore, this study supports the call for new research approaches that investigate the actual or lived experience [2].

The following sections provide a description of the research methodology and a discussion of the results. The final sections of the study present conclusions and implications.

\section{RESEARCH METHODOLOGY}

A literature review was performed to identify and classify digital assets in a project context. The "ISO 21500:2012, Guidance on Project Management" [11], APM Body of Knowledge 6th Edition [10], and A Guide to the Project Management Body of Knowledge (PMBOK guide) [9] project management standards were reviewed to identify the project artifacts that could be digital assets. Although criticized by some researchers, the "standards have come to represent an institutionalized collective identity of project managers" [19, p. 37]. Therefore, they offer guidelines for identifying project data sources. From the list of project artifacts, the keywords for the file content, and knowledge areas were compiled into a list.

Journals that focus on project management (i.e., Project Management Journal (PMJ), International Journal of Project Management (IJPM), and IEEE Transactions on Engineering Management (IEEE) [2] and International Journal of Managing Projects in Business (IJMPB)) for the years $2000-2020$ were selected for the keyword search. The bibliographic data for these journals were downloaded from the Emerald, ScienceDirect, IEEE Xplore, or Sage databases into the Endnote reference system. A set of keyword search queries were created for each project management knowledge area. Each query included the selection criteria for any keyword in the data type from the file abstract, any keyword in the file content from the abstract, and any keyword for that knowledge area from the title. An additional query set included any article with digital in the abstract, title, or keyword. The cumulated search queries produced a list of 360 unique articles.

The abstracts for the 360 articles were reviewed to determine if the article described the content or production of a digital project artifact. Based on the abstract review, 97 articles were identified as potentially relevant to the research topic. The full-text review of the 97 articles produced 48 articles that described digital assets in sufficient detail to support the classification. Table I summarizes the number of journal article reviewed for the study.
The coding strategy used to identify and classify digital assets was customized from the classification categories provided by [3] and [20]. In Snider, Gopsill, Jones, Emanuel and Hicks [3], digital assets were classified as digital communication between actors, virtual representations and models of project objects, or textual or numerical documents. That study created decision support monitoring processes based upon the physical attribute (e.g., size or dates), content, or context (e.g., origin, project stage) of the digital asset. Those attributes were not considered in this study.

Quinton and Reynolds [20] specified the dimensions of the data, including data type (attitudinal or behavioral), distances from the data source (primary or secondary), data generation (mythically manufactured or naturally occurring), and data visuality (public or private). They also specified the characteristics of the dataset (big data, open data), the information (encoding format, provider), usage, and ethical challenges. In this study we grouped digital assets using the data dimensions from [20] as well as attributes from our conceptual model.

After collecting and reviewing all articles within the defined scope, we compiled a list of digital assets that met the criteria and developed the classification framework for the articles and for the digital assets. Fig 1. includes the digital assets. For space reasons the digital classification details are excluded from the paper. The digital classification tables are available upon request to the author.

\section{DigITAL ASSET CLASSIFICATION}

Digital assets that were described in the literature were defined and classified. The digital assets were grouped into the communication between actors, virtual representation or models, and records and reports. The research found that the digital assets are embedded in computer systems such as Computer-aided design (CAD), Geographical Information System (GIS), project management information system (PMIS), project scheduling, social media applications, telecommunication or internet meeting platforms, or

TABLE I.

JOURNAL ARTICLES

\begin{tabular}{lcccc}
\hline JOURNAL & $\begin{array}{c}\text { TOTAL } \\
\text { ARTICLES }\end{array}$ & $\begin{array}{c}\text { SCREENED } \\
\text { ARTICLES }\end{array}$ & $\begin{array}{c}\text { FULL-TEXT } \\
\text { REVIEW }\end{array}$ & $\begin{array}{c}\text { WITH } \\
\text { DIGITAL } \\
\text { ASSETS }\end{array}$ \\
\hline IEEE & 1401 & 124 & 34 & 16 \\
\hline IJMPB & 644 & 54 & 14 & 5 \\
\hline IJPM & 1918 & 139 & 37 & 19 \\
\hline PMJ & 1080 & 43 & 12 & 8 \\
\hline \hline TOTAL & $\mathbf{4 4 1 4}$ & $\mathbf{3 6 0}$ & $\mathbf{9 7}$ & $\mathbf{4 8}$
\end{tabular}


Fig. 1 Digital Asset Classification

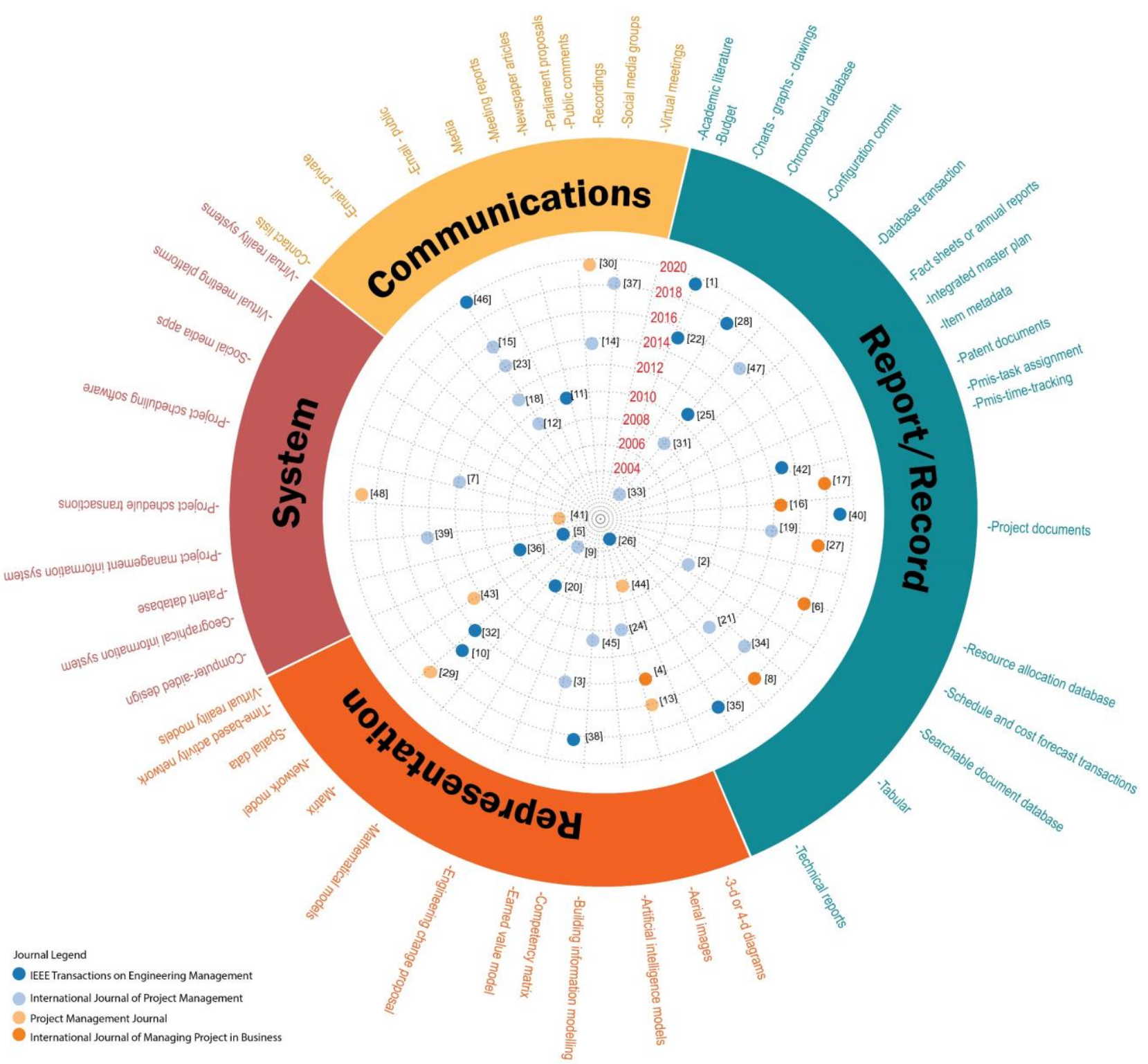

The figure is an overview of the digital asset classifications with the asset names in the outer circle grouped by category. In the inner circle is a reference number for the journal paper and a color code for the publication. The articles are aligned by the year along the radius and the digital asset along the circumference. The article references are not included in the paper due to space limitation, but the article list is available upon request.

virtual reality technologies. The data that can be extracted as exports, database transactions, or tabular records from such systems are classified in the study. The digital assets were classified using the following characteristics.

The digital asset is a descriptive name for the type of data artifact. The description identifies the main purpose of the asset. Data type identifies the data as attitudinal or behavioral. Attitudinal data describes what people say, and behavioral data describes what people do. The data source identifies the variable as a primary source where raw data can be collected with a specific question in mind (e.g., an email) or a secondary source where the data has already been filtered or interpreted by someone such as the project manager (e.g., a status) or a model. Visibility identifies the location and ownership of the data. The options include public-public, private-public, private-private, or open. Public-public data are public data that are accessible from a public location; private-public is private data that are located in a public place usually with access controls; private-private is confidential to a specific individual or 
group, and open are public data from a public source such as local or government projects. The encoding identifies the format of the data. The data can be text, numeric, images, recordings, videos. The project artifact can be inputs or outputs of project activities or analytical transformations. Since the papers used a variety of names to describe similar content, names from the project management standards were used. Reference(s) (Ref) identifies the articles in which the asset was discussed.

\section{CONCLUSION}

In this study, we compiled a list of digital assets that could be used for project studies or for creating data-driven project management processes. This digital asset classification provides a source for primary and secondary data.

The practical implications are a list of digital assets that can be inputs in the creation of project artifacts and sources for monitoring and controlling project activities and for sense-making in retrospectives or lessons learned. Moreover, this categorization is useful for decision support and artificial intelligence systems model development that requires raw data.

Projects offer a rich environment for where the time and actors are usually fixed at the start of the project. Thus, they are ripe for applying multiple research methods such as action research, case study, and experiments. Digital assets support tracing individual, group, and organizational behaviors. Furthermore, digital data are especially relevant as organizations transition to digital and remote working environments. This categorization offers academic researchers a catalog of data sources and analysis methods for studying complex project phenomena. However, there may be some challenges gaining permission and clearance to utilize the data in the desired method. In addition, ethical use is a concern when dealing with data related to individuals.

This study is limited by the sources used for its investigation. This research was based on a literature review at a single point in time and focused on a small selection of publications. Further research with project and organizational actors is needed to expand on the types of digital assets and further classify the data. An interesting extension would be to add the attributes relevant to each digital asset to the classification model.

\section{REFERENCES}

[1] R. A. Lundin and A. Söderholm, "A theory of temporary organization," Scandinavian Journal of Management, vol. 11, no. pp. $437-455,1995$.

[2] N. Drouin, R. Müller, and S. Sankaran, Novel Approaches to Organizational Project Management Research: Translational and Transformational. Denmark: Copenhagen Business School Press, 2013.

[3] C. Snider, J. A. Gopsill, S. L. Jones, L. Emanuel, and B. J. Hicks, "Engineering Project Health Management: A Computational
Approach for Project Management Support Through Analytics of Digital Engineering Activity," IEEE Transactions on Engineering Management, vol. 66, no. 3, pp. 325-336, 2019, https://doi.org/10.1109/TEM.2018.2846400.

[4] A. Jensen, C. Thuesen, and J. Geraldi, "The Projectification of Everything: Projects as a Human Condition," Project Management Journal, vol. 47, no. 3, pp. 21-34, Jun 2016, http://dx.doi.org/10.1177/875697281604700303.

[5] R. A. Lundin, "Project Society: Paths and Challenges," Project Management Journal, vol. 47, no. 4, pp. 7-15, Aug 2016, http://dx.doi.org/10.1177/875697281604700402.

[6] J. Geraldi and J. Söderlund, "Project studies and engaged scholarship: Directions towards contextualized and reflexive research on projects," International Journal of Managing Projects in Business, vol. 9, no. 4, pp. 767-797, 2016 , http://dx.doi.org/10.1108/IJMPB-02-2016-0016.

[7] C. Besner and B. Hobbs, "An Empirical Identification of Project Management Toolsets and a Comparison Among Project Types," Project Management Journal, vol. 43, no. 5, pp. 24--46, 2012, https://doi.org/10.1002/pmj.21292.

[8] H. K. Doloi, "Understanding stakeholders' perspective of cost estimation in project management," International Journal of Project Management, vol. 29, no. 5, pp. 622-636, Jul 2011, https://doi.org/10.1016/j.ijproman.2010.06.001.

[9] PMI, "A Guide to the Project Management Body of Knowledge (PMBOK Guide) --Sixth Edition," Sixth Edition ed. Newtown Square, Pennsylvania, United States: Project Management Institute, Inc., 2017.

[10] APM, "APM Body of Knowledge 6th Edition," ed. Buckinghamshire, United Kingdom: Association for Project Management, 2012.

[11] ISO, "ISO 21500: 2012 Guidance on project management," vol. International Standards Organization, ed. Geneva, Switzerland, 2012.

[12] S. Duffield and S. J. Whitty, "Developing a systemic lessons learned knowledge model for organisational learning through projects," International Journal of Project Management, vol. 33, no. 2, pp. 311-324, Feb 2015, https://doi.org/10.1016/j.ijproman.2014.07.004.

[13] J. Whyte, "How Digital Information Transforms Project Delivery Models," Project Management Journal, vol. 50, no. 2, pp. 177194, Apr 2019, http://dx.doi.org/10.1177/8756972818823304.

[14] K. S. K. Chung and L. Crawford, "The Role of Social Networks Theory and Methodology for Project Stakeholder Management," Procedia - Social and Behavioral Sciences, vol. 226, no. pp. 372380, Jul 2016, https://doi.org/10.1016/j.sbspro.2016.06.201.

[15] L. Hossain and A. Wu, "Communications network centrality correlates to organisational coordination," International Journal of Project Management, vol. 27, no. 8, pp. 795-811, Nov 2009, https://doi.org/10.1016/i.ijproman.2009.02.003.

[16] M. Takahashi, M. Indulska, and J. Steen, "Collaborative Research Project Networks," Project Management Journal, vol. 49, no. 4, pp. 36-52, Aug 2018, http://dx.doi.org/10.1177/8756972818781630.

[17] L. L. Willems and M. Vanhoucke, "Classification of articles and journals on project control and earned value management," International Journal of Project Management, vol. 33, no. 7, pp. 1610-1634, Oct 2015, https://doi.org/10.1016/j.ijproman.2015.06.003.

[18] H. R. Nemati, D. W. Todd, and P. D. Brown, "A hybrid intelligent system to facilitate information system project management activities," Project Management Journal, vol. 33, no. 3, pp. 4252, Sep 2002, https://doi.org/10.1177\%2F875697280203300306.

[19] P. Eskerod and M. Huemann, "Sustainable development and project stakeholder management: what standards say," International Journal of Managing Projects in Business, vol. 6, no. $1, \quad$ pp. $36-50, \quad 2013$, https://doi.org/10.1108/17538371311291017.

[20] S. Quinton and N. Reynolds, Understanding research in the digital age: Sage, 2018. 